\title{
INNOVATOR OR COPYCAT? PRE-ENTRY INNOVATION STRATEGY AND EARLY PERFORMANCE OF SPIN-OUTS
}

\author{
SASCHA G. WALTER \\ Lancaster University Management School \\ Lancaster LA1 4YX, UK \\ SIMON HEINRICHS \\ Hermes Fulfilment GmbH, Hamburg, Germany \\ ACHIM WALTER \\ Christian-Albrechts-University Kiel, Germany

\section{INTRODUCTION}

Spin-outs (entrepreneurial ventures by ex-employees) are said to spawn with a valuable 'legacy', namely critical knowledge and routines that are transferred from the former employer through the founders' experience (Agarwal, Echambadi, Franco, \& Sarkar, 2004). Although such knowledge advantages enable spin-outs to outperform other new entrants (Agarwal \& Shah, 2014), spin-outs tend to vary in how they use transferred knowledge. Some act as simple replicators ("rapacious plunderers", Klepper, 2001: 639): They exploit knowledge absorbed from the parent firm without further differentiating the spin-out's knowledge base (Bhidé, 2000; Phillips, 2002). Others are strong innovators (“operating at the forefront of innovation”, Agarwal et al., 2004: 501): They explore discoveries which the founders claimed for themselves or which the parent was not able or not willing to pursue, thereby setting themselves apart from the parent (Hellmann, 2007; Klepper \& Sleeper, 2005). But which innovation strategy is more likely to enhance spin-out growth, in particular in the critical early stage? Exploitation ("refinement and extension of existing competencies, technologies, and paradigms”, March, 1991: 85), exploration (“experimentation with new alternatives”, March, 1991: 85), or both together?

In investigating these questions, our study draws on the knowledge-based view (e.g., Grant, 1996a) and theories of organizational learning (e.g., March, 1991) to explore how preentry product innovation strategies affect the early growth of spin-outs. We focus on the preentry stage, i.e. the time before achieving the first sale, as parenting advantages are highest and critical routines become imprinted during that time (Phillips, 2002; Wezel, Cattani, \& Pennings, 2006). Specifically, this paper makes three core arguments: (1) Either very low or very high levels of pre-entry exploitation are optimal, i.e. there is a U-shaped relationship between preentry exploitation and early sales growth of spin-outs, (2) pre-entry exploration has the highest performance impact at moderate levels, i.e. there is an inverted U-shaped relationship between pre-entry exploration and sales growth, and (3) spin-outs need to focus on one or the other in the early phase, i.e. ambidexterity, in terms of combining or balancing exploitation and exploration, has a detrimental effect on sales growth.

\section{THEORECTICAL DEVELOPMENT}

From a knowledge-based perspective, the main role of firms is the integration of specialist knowledge (Grant, 1996b). Despite the many advantages of knowledge transfers, spinouts were found to vary in the extent to which they incorporate parent knowledge into their 
initial knowledge bases (Agarwal, Campbell, Franco, \& Ganco, 2011; Basu et al., 2015; Sapienza et al., 2004). Such variance can reflect different learning approaches that the founders adopt after identifying a business opportunity as employees of the parent firm. Following March (1991), we distinguish two approaches. The first, pre-entry exploitation, emphasizes efficiency by drawing on the founders' existing knowledge base, which may, in the case of spin-outs, largely consist of knowledge and routines carried over from prior employment. The founders focus on local search and activities characterized by "refinement, choice, production, efficiency, selection, implementation, and execution” (March, 1991: 71). The second approach, pre-entry exploration, requires to shift away from the founders' existing knowledge base. It involves distant search and is typically associated with "search, variation, risk taking, experimentation, play, flexibility, discovery, and innovation” (March, 1991: 71). The learning approach has important implications for how the spin-out is positioned within the competitive landscape (Klepper, 2001), relates to the parent (Walter et al., 2014), engages in boundary spanning (Gruber, MacMillan, \& Thompson, 2008), recruits co-founders and employees (Agarwal et al., 2011) and, as we will argue later, performs at early stages. The learning approach may manifest in the nature of a spin-out's first product offers. Some spin-outs decide to imitate their parents' know-how and offer the same products as their parents (Franco \& Filson, 2006). This enables them to swiftly enter markets at low costs, but entails significant risks of parent retaliation (Klepper \& Sleeper, 2005). Other spin-outs draw on parents' knowledge by developing cheaper or better variants of their products, differentiated enough to discourage retaliation by the parent (Fern, Cardinal, \& O'Neill, 2012; Klepper, 2001). Still other spin-outs clearly distance themselves from their parents by introducing own and novel products.

\section{Pre-entry exploitation and early sales growth}

Some scholars view spin-outs as extensively capitalizing on knowledge transferred from incumbents (Basu et al., 2015; Bhidé, 2000). However, spin-outs take differ in how they transfer and use knowledge. Some spin-outs directly apply parent know-how to create copies of their parents’ products (Klepper \& Sleeper, 2005). This approach highlights imitation and may imply a low level of exploitation. The spin-out focuses on manufacturing, while minimizing overhead and development costs to make the spin-out price-competitive (Ansoff \& Stewart, 1967).

Although this approach creates redundancies and is thus unconducive to long-lived competitive advantage (Grant, 1996a), it may be an economical learning logic (Fern et al., 2012) and support spin-out growth especially in early life stages through a cost advantage (Klepper, 2001; Phillips, 2002). For instance, reliance on parent knowledge cuts R\&D costs (Chatterji, 2009) and the market share needed for profitability (Klepper, 2001). Using proven business concepts allows to effectively address customer needs without the costly and uncertain trial-and-error processes typically associated with new product development and other learning strategies (Beckman, 2006; Clarysse et al., 2011). In contrast, other spin-outs use inherited knowledge to develop variants of their parents’ products (Klepper \& Sleeper, 2005), which emphasizes the refinement of existing knowledge and thus implies a high level of exploitation (March, 1991). A spin-out pursuing refinement redesigns a parent's product by changing the core technical and user service features of the product (Katila \& Ahuja, 2002). The spin-out engages in activities involving some development, no research, and considerable cost consciousness (Ansoff \& Stewart, 1967). The focus rests on differentiating from the parent while still benefiting from knowledge carry-overs. Although this incurs higher costs than pure imitation, refinement is likely to still create cost advantages as it makes errors and false starts less likely and allows to rely on existing routines 
(Katila \& Ahuja, 2002). Moreover, product modifications enable the spin-out to occupy niches, while still benefiting from knowledge transfers (Clarysse et al., 2011) and reducing the risk of parent retaliation (Walter et al., 2014). Such modifications also involve reconfiguring existing, transferred knowledge, thereby increasing competitiveness (Grant, 1996b) and helping the spinout in develop products with unique features for customers, which in turn enhances early sales growth.

Diverging from a concentrated imitation or refinement strategy (in other words: the middle of the U-shape) is likely to lead to lower early sales growth. First, the cost advantage of imitation may drop disproportionally with greater pre-entry exploitation because redesigning existing products typically requires additional investments, e.g. hiring new staff, and thus incurs, at some level of innovation, greater fixed costs. Second, the benefits of refinement may diminish disproportionally with lower pre-entry exploitation. Klepper (2001) argues that it is often unprofitable for parent firms to retaliate against sufficiently differentiated spin-outs. However, if differentiation falls below a threshold, a cost-benefit rationale will lead the parent to retaliate, thereby rendering one key advantage of refinement for the spin-out obsolete. Third, spin-outs focusing neither on imitation nor on refinement are prone to be "stuck in the middle", offering products that are too expensive to generate a cost advantage and not unique enough for a differentiation advantage (Dess \& Davis, 1984). Thus, ceteris paribus,

Hypothesis 1: The relationship between pre-entry exploitation and early sales growth is U-shaped.

\section{Pre-entry exploration and early sales growth}

In a popular view, distant search helps spin-outs overcome their parents' inertia and barriers to path-breaking knowledge creation (Basu et al., 2015), while still benefiting from knowledge and relationship advantages over other types of entrants (Agarwal et al., 2004; Klepper \& Thompson, 2010). The spin-out does not rely solely on 'inherited' knowledge but differentiates from the parent by substantially integrating novel knowledge elements into its knowledge base (Clarysse et al., 2011). This emphasis on exploration enables the spin-out to enter market niches with own, innovative products (Anton \& Yao, 1995; Chatterji, 2009) and creates opportunities for future exploitation (Lavie et al., 2010). Pre-entry exploration is, as we argue now, positively related to early sales growth of spin-outs up to a turning point, after which it becomes negative. First, exploration generates several differentiation advantages vis-à-vis competitors. For instance, the spin-out's knowledge base becomes more robust towards imitation and substitution, the more it comprises novel knowledge elements and is characterized by causal ambiguity (Grant, 1996b). This is conducive to temporary monopolistic positions in the market, first mover advantages, and long-term financial performance (Bierly \& Daly, 2007). Moreover, differentiation reduces competitive tension with the parent, thereby making the parent more likely to support and subcontract to the spin-out (Lindholm Dahlstrand, 1997). Second, exploration involves and fosters learning conducive to spin-out growth. A spin-out that integrates knowledge items not held in common with the parent is more likely to arrive at technological innovations (Fleming, 2001) and create path-breaking knowledge with greater sales potential (Quintana-García \& Benavides-Velasco, 2008).

However, the literature also points to two negative effects of excessive exploration. First, a greater emphasis on exploration incurs dynamically increasing risks and costs. Exploration creates high levels of risks because it requires to leave known knowledge territory (Rosenkopf \& 
Nerkar, 2001), disrupts existing capabilities and relationships (Abernathy \& Clark, 1985) and yields returns that are hardly predictable and may materialize over a long period, if at all (Lubatkin et al., 2006). Exploration amplifies costs because the more novel and the broader in scope the knowledge to be integrated, the more complex are the organizational and technical challenges to manage the integration (Katila \& Ahuja, 2002). Reconfiguring existing knowledge is costly and impairs knowledge integration (Grant, 1996b). Overreliance on exploration can thus result in a high cost burden without immediate payback, making the spin-out vulnerable to competitors (Lubatkin et al., 2006) and possibly leading to a cycle of search, failure and unrewarded change (Raisch \& Birkinshaw, 2008). Second, excessive exploration diminishes the knowledge advantage of spin-outs. Overlaps in organizational knowledge facilitate interfirm knowledge transfers (Grant, 1996a). Exploration increases the distance in the knowledge bases of spin-out and parent, which impairs further knowledge transfers between the two firms (Sapienza et al., 2004) and deteriorates the value of 'inherited' network contacts (Henderson \& Clark, 1990). Therefore, the costs and risks of exploration will eventually exceed its benefits. Thus, ceteris paribus,

Hypothesis 2: The relationship between pre-entry exploration and early sales growth is inverted U-shaped.

\section{Organizational ambidexterity and early sales growth}

The organizational learning literature has suggested that simultaneous organizational ambidexterity, i.e., combining and/or balancing exploration and exploitation at the same time, yields superior firm performance (He \& Wong, 2004; O'Reilly III \& Tushman, 2004; Raisch, Birkinshaw, Probst, \& Tushman, 2009). However, this argument, as we will propose next, does not apply to spin-outs that may rather benefit from a focused strategy for several reasons. First, simultaneous organizational ambidexterity scatters founder attention and spin-out resources. It creates a complexity making the founding team more likely to suffer from information overload and to engage in suboptimal decision-making driven by heuristics and biases (Katila \& Ahuja, 2002; Rothaermel, Hitt, \& Jobe, 2006). Therefore, undertaking multiple and diverse changes in a firm's knowledge base at the same time is problematic and prone to failure (Henderson \& Clark, 1990; Yayavaram \& Chen, 2015). Moreover, young firms are typically characterized by unclear boundaries of responsibility and role ambiguity between marketing, design and manufacturing functions, which increases coordination problems and costs caused by a complex product innovation strategy (Fernhaber \& Patel, 2012). While organizational slack allows larger firms to manage the tension between exploitation and exploration in separate specialized subunits, this option is often unavailable to resource-constrained spin-outs (Ebben \& Johnson, 2005).

Engaging in exploration creates additional search costs that limit the resources available for exploitation (Gruber et al., 2008). Thus, resource constraints can lead small firms to pursue a focused strategy (Mc Namara \& Baden-Fuller, 2007; Voss \& Voss, 2013) or sequential rather than simultaneous ambidexterity (O'Reilly III \& Tushman, 2013). For instance, Brown and Eisenhardt (1997) found that small electronics firms oscillate back and forth between exploitation and exploration over time. In a case study by Laplume and Dass (2015), a firm engaged in sequential ambidexterity for about 20 years before also considering simultaneous ambidexterity.

Second, since exploitation and exploration are based on different learning approaches and knowledge bases, pursuing them simultaneously slows down the acquisition, integration and 
creation of new knowledge. For instance, Lubatkin et al. (2006) suggest that ambidexterity involves managing conflicting knowledge processes. Similarly, Grant (1996b) highlights the tradeoff between knowledge breadth and depth. According to Ansoff and Stewart (1967), different innovation strategies require different 'couplings' between functional areas such as RD, operations, marketing and logistics, which results in different degrees of cross-functional knowledge integration. Moreover, the two innovation strategies require different knowledge bases, which is closely linked to the initial composition of the founding team (Beckman, 2006). An increasing focus on exploration may require more co-founders from outside the parent firm because prior knowledge constrains the identification of new opportunities (Shane, 2000) and because having a broader set of knowledge provides better possibilities for recombining the founders' different knowledge endowments to find novel solutions (Fleming, 2001; Gruber, 2010). In contrast, exploitation may benefit from a homogenous team from within the parent firm because existing routines and shared language facilitate communication and further knowledge transfers from the parent (Sapienza et al., 2004). Ambidexterity can impair team decision making because, depending on the team composition, a preference and stronger competence for exploitation or exploration may prevail (Fern et al., 2012; Gruber et al., 2008). Thus, ceteris paribus,

Hypothesis 3a: Simultaneous organizational ambidexterity, in terms of combining high levels of both exploitation and exploration, is negatively related to early sales growth.

Hypothesis 3b: Simultaneous organizational ambidexterity, in terms of balancing exploitation and exploration, is negatively related to early sales growth.

\section{METHODS}

The study draws on primary data from 154 technology spin-outs in Germany. The average spin-out was eight years old $(\mathrm{sd}=3.05)$, had $26(\mathrm{sd}=88.54)$ full-time employees, and operated in the technological fields of software (34\%), electronics (28\%), nanotechnology and new materials (10\%), biotechnology (9\%), and others (19\%).

Dependent variable. Following Hmieleski and Baron (2009), early sales growth was measured as the average annual revenue growth over the first three fiscal years after the year of market entry. Sales were reported by the respondent. Previous research has shown that selfreported sales and venture performance measures are reliable (Brush \& Vanderwerf, 1992).

Independent variables We adapted existing scales for pre-entry exploration $(\alpha=.72)$ and pre-entry exploitation ( $\alpha=.79$ ) developed and validated by Jansen et al. (2006). While the original scale comprised aspects of both product and market innovation, we considered only items related to product innovation, the focus of our study.

Control variables. We controlled for technological fields (dummy variables for biotechnology, electronics, nanotechnology and new materials, and software), parent hostility (dummy, coded 1 for a hostile parent and 0 otherwise), competitive intensity (three items, $\alpha=$ .75), market growth (three items, $\alpha=.81$ ) and market turbulence (three items, $\alpha=.75$ ).

\section{RESULTS}

In line with Hypothesis 1, pre-entry exploitation had an inverted U-shaped relationship with early sales growth (Model $2, \mathrm{~b}=.23, \mathrm{p}<.01$ ). Providing (weak) support for Hypothesis 2, 
the relationship between pre-entry exploration and early sales growth was U-shaped (Model 3, b $=-.03, \mathrm{p}<.10$; Model 6, $\mathrm{b}=-.04, \mathrm{p}<.05)$. Further tests suggested by Lind and Mehlum (2010) confirmed the significance of the curvilinear relationships. Hypothesis 3a received support as the relationship between pre-entry exploitation and early sales growth was negatively moderated by pre-entry exploration (Model 4, b = -.11, p <.001). Overall, the early sales growth of spin-outs suffers from simultaneously pursuing high levels of exploitation and exploration. To test Hypothesis 3b, we calculated the absolute difference between exploration and exploitation and subtracted the resulting score from 7 so that higher values reflect greater balance (Cao, Gedajlovic, \& Zhang, 2009). The balance term was negatively and significantly related to early sales growth (Model 5, b = -.17, p <.01), which supported Hypothesis 3b. This suggests that the early sales growth of spin-outs diminishes more, the more they balance pre-entry exploitation and exploration. Among the control variables, parent hostility had the expected negative sign, but was not significantly related to early sales growth (Model $1, \mathrm{~b}=-.10$, ns). Walter et al. (2014) reported a negative hostility impact on profitability, in terms of increasing time to breakeven. One explanation is that our sales measure captures the volume increase, but not the profitability of sales.

\section{DISCUSSION}

This research makes two core contributions to the extant literature. First, our findings add to an emerging stream in the spin-out literature that examines the role of 'inherited' knowledge for the development of spin-outs. Some scholars viewed transferred knowledge as a valuable asset enhancing spin-out survival and performance (Agarwal et al., 2004, Andersson et al., 2012, Chatterji, 2009). Other scholars proposed that spin-outs benefit from partial rather than excessive overlaps with the parent's knowledge base (Basu et al., 2015; Sapienza et al., 2004). In contrast, our findings suggest three growth-maximizing strategies involving different levels of 'inherited' knowledge, namely imitation (very low levels of exploitation), refinement (very high levels of exploitation), and moderate innovation (mid-levels of exploration). Thus, instead of generally viewing spin-outs as drivers of major innovations (Agarwal et al., 2004), we theorize on spinouts as varying greatly in their preferred innovation strategy, ranging from pure imitation to moderate innovation. Second, our study contributes to the organizational learning literature by demonstrating that pre-entry exploitation and pre-entry exploration have curvilinear relationships with firm growth - a possibility typically disregarded by ambidexterity researchers (with a few notable exceptions, e.g., Bierly \& Daly, 2007). In particular, we found different non-linear effects of exploitation and exploration, with the prior being optimal at extreme (very low or high) levels and the latter at mid-levels. The literature has long acknowledged that large and rich firms rather than resource-constrained SMEs are likely to benefit from simultaneous organizational ambidexterity (Raisch \& Birkinshaw, 2008). Our study confirms this notion also in a spin-out context but suggests an alternative explanation for why simultaneous organizational ambidexterity is counterproductive for small firms: Given their disparate non-linear effects, the mechanisms behind exploitation and exploration are incompatible and countervailing, which makes their simultaneous application no viable option for spin-outs.

\section{REFERENCES AVAILABLE FROM THE AUTHOR(S)}

